\title{
Escritura y fragmento: la política del gesto en Roland Barthes
}

\author{
Francisco Javier CERÓN LUNA \\ Universidad Nacional Autónoma de México
}

En este texto se propone una lectura metodológica de la obra de Roland Barthes a partir del cuestionamiento de la escritura como inestabilidad significante del lenguaje. Se invita a repensar, entonces, la idea de escritura de este autor desde cuatro perspectivas: como un espacio neutral, como una estructura significante, como un esbozo de una teoría del texto y como una apuesta plástica que nace del fragmento. Esta última perspectiva es leída desde la política del gesto que propone el filósofo italiano Giorgio Agamben para, así, enunciar que la posición intelectual de Barthes retoma el desbordamiento del lenguaje como imposibilidad de cierre del sentido.

PALABRAS ClAVE: escritura, estructura significante, fragmento, política del gesto, teoría del texto.

This paper proposes a methodological reading of Roland Barthes' work and his questioning of writing as an unstable signifier of language. Thus, it invites us to rethink the author's idea of writing from four different perspectives: as a neutral space, as a signifier structure, as a draft of a text theory, and as a plastic proposal emerging from the fragment. This last perspective can be read from the politics of gesture, which the Italian philosopher Giorgio Agamben proposes to enunciate that Barthes' intellectual position picks up the overflow of style as impossibility for closure of the sense.

KEY WORDS: writing, signifier structure, fragment, politics of gesture, text theory.

La escritura no es en modo alguno un instrumento de comunicación, no es la vía abierta por donde sólo pasaría una intención del lenguaje. Es todo un desorden que se desliza a través de la palabra y le da ese ansioso movimiento que la mantiene en un estado de eterno aplazamiento.

Roland Barthes, El grado cero de la escritura

Roland Barthes no podía ser menos celebrado en su centenario. Autor camaleónico, inclasificable, como alguna vez lo llamó Michel Foucault. Justo así, el número especial de julio y agosto de 2015 del periódico Le Monde en Francia subtitulaba el dossier de 
la presentación de la vida y obra de Barthes como el "centenario de un revolucionario del lenguaje"; pero también dejaba entrever tímidamente un epíteto: "Barthes, el inesperado". No podríamos catalogar mejor la obra intelectual y el espíritu reflexivo de este autor: uno que se enfrenta al lenguaje, ese inesperado que siempre nos desborda.

¿En qué sentido podríamos repensar a Roland Barthes como un revolucionario del lenguaje? Tendríamos que recordar que desde sus primeros escritos, aquel de El grado cero de la escritura, el lenguaje sería la preocupación, casi obsesiva, de su trabajo. Y es justamente bajo la égida de las transformaciones y de las convulsiones de la lengua, que la obra de Roland Barthes se va transformando. De un intelectual preocupado por la estructura significante (cuyo mejor ejemplo sería el brillante Introducción al análisis estructural de los relatos) y de una teoría textual inclinada por un erotismo del lector (El placer del texto), hasta las preocupaciones más plásticas (a modo del bricolaje que anima, según Jacques Derrida, toda desestructuración de los saberes) que podrían ser los Fragmentos de un discurso amoroso o su pseudoautobiografía Roland Barthes por Roland Barthes.

Hay una preocupación constante en Barthes: la indescifrable transformación del lenguaje, misma que nos gustaría explorar como forma de vida intelectual que el semiólogo francés nos ofrece en su obra: una política del gesto basada en el fragmento; como lo enuncia el filósofo italiano Giorgio Agamben: "por medio de él [el gesto] no se produce ni se actúa, sino que se asume y se soporta" (2001: 53). Queremos, entonces, visualizar si en los "medios", a veces truculentos, a veces charlatanes, de la escritura, Barthes podría invitarnos a asumir un compromiso: una escritura que anima a refundarlo todo, que se repiensa a ella misma, que nos obliga a mirar de frente la luz, siempre cegadora, del pasado lapidario para reconstruirlo desde sus ruinas, desde los fragmentos que terminamos siendo, de algún modo, todos en este mundo.

\section{La obsesión de la escritura}

La presencia de la lengua, su fuerza vital, o mejor enunciado, la actualización de la lengua en la escritura, será uno de los hilos conductores del trabajo de Roland Barthes. Pero su concepción de la escritura sufrió varios cambios. Proponemos observar cuatro etapas para delinear las miradas de Barthes sobre la escritura: lo neutro, la estructura, el texto y el fragmento; tipología que no responde a un ánimo genealógico, sino metodológico.

Después de varias publicaciones parciales en la revista Combat, en 1953 ve la luz Le degré zéro de l'écriture. En esta obra, Barthes ensaya un proyecto de delimitación de la escritura moderna, o de lo que significa escribir en la modernidad donde la trascendencia metafísica ha perdido toda su potencialidad:

[L]'écrivain devient la proie d'une ambiguïté, puisque sa conscience ne recouvre plus exactement sa condition. Ainsi naît un tragique de la Littérature. 
C'est alors que les écritures commencent à se multiplier. Chacune désormais, la travaillée, la populiste, la neutre, la parlée, se veut l'acte initial par lequel l'écrivain assume ou abhorre sa condition bourgeoise. Chacune est une tentative de réponse à cette problématique orphéenne de la Forme moderne: des écrivains sans littérature (Barthes, 1972: 45).

Barthes delinea que, a diferencia del siglo XIX, la literatura de la posguerra, aquella que lleva la huella del genocidio, ya no puede representar una totalidad significante: la escritura moderna es el fragmento del hombre, es una especie de punto de partida, y al mismo tiempo, un límite mínimo a donde tiende toda literatura: "La nouvelle écriture n'implique aucun refuge, aucun secret; on ne peut pas dire que c'est une écriture impassible, c'est plutôt une écriture innocente" (Barthes, 1972: 56). Por ello, como lo pensara Maurice Blanchot, la escritura es ese blanco, esa pureza mínima, ese lugar neutro donde ya no se comunica más sino que sólo se experimenta, Barthes lo atestigua: "l'écriture neutre retrouve réellement la condition première de l'art classique: l'instrumentalité. Mais cette fois, l'instrument formel n'est plus au service d'une idéologie triomphante; il est le mode d'une situation nouvelle de l'écrivain, il est la façon d'exister d'un silence" (1972: 56, cursivas mías). Observemos, entonces, que la forma se convierte en un nuevo paradigma para Roland Barthes, mismo que inaugura su etapa estructuralista.

En L'activité structuraliste, Barthes se pregunta sobre la forma de crear sentido, a tal grado de concebir que "l'objet du structuralisme, ce n'est pas l'homme riche de certains sens, mais l'homme fabricateur de sens" (1991: 218). Para Barthes, el análisis estructuralista no es un mero procedimiento descriptivo de los objetos con significado, o, si se prefiere, la descripción que el estructuralista logra hacer ver no es anodina. Así, la literatura será un campo en el que precisamente se puede pensar estructuralmente. De este modo, las descripciones fuera de la obra resultan poco productivas, dicen poco acerca del significado de ella, menos aún, la relación entre obra y autor. Por lo tanto, es necesario adentrarse en la obra, descubrir sus unidades y sus reglas de agrupación:

[T]odo en diverso grado significa algo en él [el relato]. Esto no es una cuestión de arte (por parte del narrador), es una cuestión de estructura: en el orden del discurso, todo lo que está notado es por definición notable: aun cuando un detalle pareciera irreductiblemente insignificante, rebelde a toda función, no dejada de tener al menos, en última instancia, el sentido mismo del absurdo o de lo inútil: todo tiene un sentido o nada lo tiene (Barthes, 1970: 16-17, cursivas mías).

La escritura se presenta, así, como un desorden que hay que re-estructurar para "acceder" al significado que ella misma muestra, no para descubrirlo, sino para mostrarlo, pues el significado siempre está latente.

Aquel Barthes estructuralista, hoy una de las posiciones más polémicas que se estudian del autor, sigue preguntándose por la vigencia de la escritura, por su manifestación contemporánea. Si "lo neutro" de la escritura literaria concibe un no-más allá 


\section{$234 \square$ ESCRITURA Y FRAGMENTO: LA POLÍTICA DEL GESTO EN ROLAND BARTHES}

comunicativo, la estructura trata de manifestar una exigencia, a modo de duda, significativa de la escritura: el paso estructuralista barthiano es necesario para poder entrar al conflicto del significado entre autor, obra y lector. Ya vemos en $S / Z$ que Barthes se pregunta sobre las operaciones que arriban en el momento de la lectura: cómo la escritura se desdobla para poder significar entre el autor y el lector. Pero para no caer en la fenomenología trascendente o en la hermenéutica ontológica de la recepción literaria, Barthes se decidió por el mediador entre autor y lector: la obra concebida como texto.

La obra no es el trazo de una trascendencia, no es el velo que cubre una verdad a la cual se pretende acceder, la obra es texto. Es necesario escuchar esta diferencia en palabras de Barthes:

La obra es un fragmento de sustancia, ocupa una porción del espacio de los libros (en una biblioteca, por ejemplo). El Texto, por su parte, es un campo metodológico [...] el texto se demuestra, es mencionado según determinadas reglas (o en contra de determinadas reglas); la obra se sostiene en la mano, el texto se sostiene en el lenguaje: sólo existe extraído de un discurso [...] el Texto no se experimenta más que en un trabajo, en una producción. De lo que se sigue que el texto no pueda inmovilizarse (por ejemplo, en un estante de una biblioteca), su movimiento constitutivo es la travesía (Barthes, 1987: 175, cursivas mías).

Esta productividad del texto, la apertura de su significado, como asegura Barthes, no puede depender de una interpretación sino de su diseminación, es decir, de las lecturas múltiples del texto. De ese modo, la escritura del texto "es la destrucción de toda voz, de todo origen" (Barthes, 1987: 71). Esta idea anima la concepción de la escritura literaria que se vislumbra en El placer del texto. En este pequeño libro, Barthes nos invita a pensar el texto como tejido: "el texto se hace, se trabaja a través de un entrelazado perpetuo; perdido en ese tejido; - esa textura - el sujeto se deshace en él como una araña que se disuelve en las segregaciones constructivas de su tela" (1982: 104).

Concebir la obra como una escritura textual es entrar en el terreno del goce (jouissance), en el de la lectura, en la superficie textual; pues, como afirma Barthes, es en el texto donde el propio lenguaje se pone a prueba, en juego, para lograr significados. El trabajo de significación se hace presente perpetuamente en las múltiples lecturas del texto, pues éste "ya no considera las obras como simples mensajes, ni siquiera como enunciados (es decir, productos finitos, cuyo destino se cerraría una vez que se los hubiese emitido), sino como producciones perpetuas, como enunciaciones, a través de las cuales el sujeto sigue forcejeando" (Barthes, 2002: 150).

Sigamos con nuestra propuesta metodológica. La escritura literaria se impone en Barthes como un punto cero donde lo comunicable se desvanece para dar paso al significado de la estructura, para preguntarse por la producción de ese significado en el texto. Sin embargo, es en el funcionamiento del texto, en su forma de deslizarse, donde se trabaja el significado: ya no en su dimensión meramente lingüística, sino en la lectura textual. Esa lectura del texto es la de lo inesperado, la de lo desconcertante, la del goce: "el goce no es el que responde al deseo (lo que satisface), sino lo que lo toma 
por sorpresa, lo excede, lo desorienta, lo hace ir a la deriva" (Barthes, 1982: 25). Entremos en ese goce que será, indudablemente, el carácter fragmentario de todo texto.

\section{El fragmento como política gestual}

Tras el encargo de la editorial Seuil en 1975 de una autobiografía, Roland Barthes, casi de manera irónica, construye un ejemplo gozoso de texto: Roland Barthes por Roland Barthes. Parecía que Barthes debiera escribir su propio epitafio y así lo hizo, sin ánimo solemne, sin una posición arrogante de quien se aventura a desvelarnos sus más íntimos secretos o sus manías creativas. Barthes se hizo así mismo para presentarse como un personaje de novela, a veces en tercera persona, a veces bajo la figura de la autoficción, pero siempre ambivalente. En esta pseudoautobiografía, Barthes lega el mejor "gesto" de su pensamiento: la fragmentariedad de todo texto.

Si nos adentramos al Roland Barthes por Roland Barthes nos damos cuenta que el texto se constituye de fragmentos de pensamiento que ponen en cuestión casi todos los conceptos e ideas que el autor había trabajado: la estructura, la moda, el mito, la literatura clásica y decimonónica, el teatro, el cine, la lengua, el sentido y mayormente el texto y el fragmento. Así, experimentamos el sentido que Roland Barthes da al texto de goce, siempre fragmentario: "el que pone en estado de pérdida, desacomoda, hace vacilar los fundamentos históricos, culturales, psicológicos del lector, la congruencia de sus gustos, de sus valores y de sus recuerdos, pone en crisis su relación con el lenguaje" (Barthes, 1982: 25, cursivas mías).

Parece que el propio Barthes quiere atestiguar el devenir de una escritura que pone en suspenso el sentido, que antepone su desconfiguración como principio básico de una lectura que trabaja el texto: "el sentido, el sexo, son principios de construcción, de constitución, la diferencia tiene todas las trazas de un espolvoreo (fragmento, cláusula), de una dispersión, de un espejo, encontrar desbordamientos" (Barthes, 1997: 76). Es aquí donde podemos visualizar la concepción del fragmento: una especie de espolvoreo de significado que invita a descubrir los desbordamientos del texto y ya no su unidad constitutiva.

Concebida la escritura como fragmento, ya no es importante la unidad de la construcción del sentido (la estructura) y además se parte de una concepción textual, como aquella que se trabaja en la lectura; por lo tanto, el fragmento es la posibilidad de leer gozosamente, de hacer frente a lo desconocido, no es "encontrar, en la lectura del mundo y del sujeto, oposiciones, sino desbordamientos, intromisiones, fugas, deslizamientos, desplazamientos, desbarramientos" (Barthes, 1997: 76). Ir hacia y en el fragmento, leer la literatura como fragmentos de sentido, es, entonces, una apuesta casi ética del quehacer literario.

En esta perspectiva, queremos hacer un desplazamiento hacia la filosofía de Giorgio Agamben. Este filósofo italiano se ha caracterizado por ejercer una arqueología del lenguaje: rastrear la desestructuración de los conceptos que usamos para pensar la 
modernidad, particularmente, dentro de la filosofía política. En Medios sin fin, texto construido de manera fragmentaria, invita a reflexionar sobre el gesto. El autor parte de una dualidad: el gesto como fijación de una trascendencia (la escultura o la pintura, por ejemplo) y el gesto como el recuerdo de una trascendencia (la fotografía en el sentido de imagen: lo que está en lugar de otro). El gesto también puede tensar esa relación pues exhibe un movimiento que se perpetúa (el cine sería el mejor arquetipo al concebirse como imágenes en movimiento). Así, lo característico del gesto, de la gestualidad, no es el movimiento en sí, sino la medialidad, es decir, la puesta en juego de los medios que se representan a sí mismos.

Reflexionemos sobre la figura cinematográfica del gag como gesto. El gag se utiliza en el cine para, a través de imágenes o movimientos siempre faltos de palabra, transmitir un efecto cómico (los clásicos pastelazos, los movimientos "chuscos" de los personajes, los tropezones, las miradas, las muecas estridentes). Lo característico del gag es su instantaneidad, casi un pestañeo, que hace presente la imposibilidad de hablar. Como el gag, el gesto sería la puesta en escena, la huella, de la pérdida del lenguaje para desbordar el sentido (sin el gag, eclipse total de la palabra, el film cómico pierde soltura o efecto de comedia); en palabras de Agamben, "el gesto es siempre, en su esencia, gesto de no conseguir encontrarse en el lenguaje, es siempre gag que indica sobre todo algo que se mete en la boca para impedir la palabra, y después la improvisación del actor para subsanar un vacío de memoria o una imposibilidad de hablar" (2001: 55). El gesto nada dice sino que muestra a través de los medios que él mismo expresa.

A modo arqueológico, quizá sirva para entender al gesto como esta imposibilidad de hablar, si nos referimos a tres vocablos de origen latino que Agamben reconstruye para entender el gesto desde la esfera de la acción. En latín existen tres verbos que indican acción: agere (actuar), facere (hacer) y gerere (algo así como gestar). Mientras que la actuación se entiende como la posibilidad de representar un papel del cual no se es autor, el verbo hacer implica la potencialidad, la elaboración de algo, como la forma clásica del autor que produce un texto. El verbo gestar tiene una alusión más política.

El diccionario de la RAE recoge dos acepciones al verbo gestar. Por un lado, con referencia a una hembra, "llevar y sustentar en su seno el embrión o feto"; por otro lado, "preparar o desarrollar algo". Gestar sería el desarrollo de los medios propicios para un acto. Mientras que hacer y actuar se enfocan en el fin por conseguir, gestar se centra en los puros medios. Así, Agamben reconoce que en la antigua República romana, el imperator (comandante militar envestido de poder supremo) no hace ni actúa, sino gerit, es decir, convierte su actuar en res gerere: "llevar a cabo algo, en el sentido de tomarlo sobre sí, asumir su responsabilidad" (Agamben, 2001: 54). Una política del gesto, entonces, es asumir la responsabilidad de los medios de acción.

¿Cuáles son los medios de acción de la escritura concebida como fragmento que desborda el sentido? La escritura misma. Agamben acentúa respecto a la escritura: "mostrar una palabra no significa que se disponga de un plano más elevado, para convertirla a partir de él en un objeto de comunicación, sino exponerla sin trascenden- 
cia alguna en su propio carácter medial, en su propio ser medio" (2001: 55), y añade: "el gesto es, en este sentido, comunicación de una comunicabilidad. No tiene nada propiamente que decir, porque lo que muestra es el ser-en-el-lenguaje del hombre como pura medialidad" (2001: 55, cursivas mías). El gesto es la medialidad sin un fin último: la escritura en grado cero, en busca de construcción de sentido, el cual se desborda fragmentariamente a lo largo de la lectura gozosa del texto.

Es sintomático que el texto de Roland Barthes por Roland Barthes abra con una serie de fotografías sobre los avatares del autor: imágenes, guiños de una vida, gestos que movilizan sin palabras al texto. Consideramos que con la acepción del gesto como medialidad sin fines, el proyecto de escritura en Barthes puede retomar una dimensión política, entendida como el compromiso, la responsabilidad, para con los medios de acción, que se traduce en una política de la responsabilidad con la vida; y en el caso de Barthes, para con la propia escritura, casi siempre literaria.

Quedaría por rastrear, entonces, si esa política del gesto opera en una relectura de la obra barthiana. No es gratuito que uno de los últimos textos de Barthes se vuelque en un análisis de la medialidad que representa la fotografía, un mostrar lo que está en otro lugar, un devenir spectrum: "La Fotografía es el advenimiento de yo mismo como otro: una disociación ladina de la conciencia de identidad" (Barthes, 2009: 33). Pensamos, así, que si reconfiguramos nuestras lecturas de Barthes basados en la fragmentariedad, podemos aceptar ese compromiso erótico de la lectura: buscar los medios que por sí mismos reconstituyan el significado del texto, en su simple medialidad (y ya no en una trascendencia interpretativa), como lo es siempre la mirada ambivalente de una fotografía: "el sentimiento irreductible de que la Fotografía, esencialmente, no es más que contingencia, singularidad, aventura" (Barthes, 2009: 40). ¿Acaso no es así el acto mismo de toda lectura?

A modo de conclusión, podemos decir que la exploración de las concepciones de escritura en Barthes nos sirvió para mostrar esta actitud gestual del autor. La escritura usa la propia escritura para desbordarse y reinventarse. Si consideremos la escritura literaria como la institución literaria y no como escritura (un medio sin un fin último), no podemos entender la fragmentariedad, último eslabón del proyecto barthiano sobre su propio discurso. La invitación es repensar nuestro quehacer literario como una política del gesto, es decir, la responsabilidad para con nuestro único medio: la escritura. Lancémonos, entonces, a esa apuesta, ser lectores gozosos de desbordamientos textuales, de una escritura que invita a redefinir nuestro compromiso para con el mundo en cada lectura.

\section{Obras citadas}

Agamben, Giorgio. 2001. "Notas sobre el gesto". Medios sin fin. Notas sobre la política. Trad. Antonio Gimeno CusPinera. Valencia: Pretextos. Pp. 47-57. 
BARTHES, Roland. 2009. La cámara lúcida. Notas sobre la fotografía. Trad. Joaquim Sala-SANAhuja. 8a. ed. Barcelona: Paidós.

2002. "Texto (teoría del)". Variaciones sobre la escritura. Trad. Enrique Folch GonzÁlEz. Barcelona / México: Paidós. (Col. Comunicaciones, 137) Pp. 137-154.

1997. Roland Barthes por Roland Barthes. Trad. Julieta FomBOnA ZuLOAGA.

2a. ed. Caracas: Monte Ávila.

. 1991. "L'activité structuraliste". Essais critiques. París: Seuil. Pp. 213-220.

1987. "De la obra al texto". El susurro del lenguaje. Más allá de la palabra y de la escritura. Trad. C. Fernández Medrano. Barcelona: Paidós. Pp. 73-82.

. 1982. El placer del texto y lección inaugural de la cátedra de semiología literaria del Collège de France. Trad. Nicolás Rosa y Óscar TeRÁn. México: Siglo XXI.

1972. Le degré zéro de l'écriture. París: Seuil.

. 1970. "Introducción al análisis estructural de los relatos". Análisis estructural del relato. Trad. Beatriz DorRioTs. 2a. ed. Buenos Aires: Tiempo Contemporáneo. (Col. Comunicaciones, 8). Pp. 9-43. 